\title{
Incidence of type 1 diabetes in Norway among children aged 0-14 years between 1989 and 2012: has the incidence stopped rising? Results from the Norwegian Childhood Diabetes Registry
}

\author{
Torild Skrivarhaug • Lars C. Stene • Ann Kristin Drivvoll • Hanne Strøm • \\ Geir Joner • Norwegian Childhood Diabetes Study Group
}

Received: 2 July 2013 / Accepted: 9 October 2013 /Published online: 23 October 2013

(C) Springer-Verlag Berlin Heidelberg 2013

\begin{abstract}
Aims/hypothesis Our study aimed to describe the incidence of type 1 diabetes in children below 15 years of age in Norway during the period 1989-2012 and to assess the regional variation during 2004-2012. We further set out to estimate the completeness of ascertainment in the Norwegian Childhood Diabetes Registry (NCDR).

Methods Incident cases of type 1 diabetes were registered in the NCDR and incidence rates were modelled using Poisson regression. Ascertainment for 2005-2008 was estimated using capture-recapture methodology by using data from the Norwegian Prescription Database (NorPD), a nationwide register established in 2004, which included insulin prescribed and dispensed at pharmacies to individual patients. Population data were obtained from Statistics Norway.
\end{abstract}

Electronic supplementary material The online version of this article (doi:10.1007/s00125-013-3090-y) contains peer-reviewed but unedited supplementary material, which is available to authorised users.

T. Skrivarhaug $\cdot$ A. K. Drivvoll $\cdot$ Norwegian Childhood Diabetes Study Group

Norwegian Childhood Diabetes Registry, Oslo University Hospital, Oslo, Norway

T. Skrivarhaug $(\bowtie) \cdot G$. Joner

Department of Paediatric Medicine, Oslo University Hospital,

P.O. Box 4950, Nydalen, Oslo 0424, Norway

e-mail: torild.skrivarhaug@medisin.uio.no

T. Skrivarhaug $\cdot$ L. C. Stene $\cdot$ A. K. Drivvoll $\cdot$ G. Joner

Oslo Diabetes Research Centre, Oslo, Norway

L. C. Stene $\cdot$ H. Strøm

Norwegian Institute of Public Health, Oslo, Norway

G. Joner

Faculty of Medicine, University of Oslo, Oslo, Norway
Results Observed incidence rates for 1989-2012 suggested three distinct time segments: in 1989-1996, the average incidence rate was 22.6 per 100,000 person-years $(95 \%$ CI 21.4, 23.7); in 1996-2004, the average incidence rate was 28.4 per 100,000 person-years $(95 \%$ CI $27.3,29.6)$; and from 2004 to 2012, the average incidence rate per 100,000 personyears was 32.7 (95\% CI 31.5, 34.0). After adjustment for age and sex, the estimated change per year was $1.8 \%$ for 1989 1996 (95\% CI $-0.07,3.6 ; p=0.059), 3.4 \%$ for $1996-2004$ $(95 \%$ CI $2.2,4.7 ; p<0.0001)$ and $0.3 \%$ for $2004-2012(95 \%$ CI $-0.9,1.6 ; p=0.64)$. The highest incidence was in the age group 10-14 years for both sexes. A significant regional variation in incidence was observed $(p<0.001)$. Completeness of ascertainment in the NCDR was estimated to be $91 \%$.

Conclusions/interpretation The previously observed increase in incidence of type 1 diabetes has levelled off and remained essentially constant at 32.7 per 100,000 person-years during 2004-2012. There is a significant variation in type 1 diabetes incidence within Norway.

Keywords Incidence of type 1 diabetes - Norwegian Childhood Diabetes Registry · Norwegian Prescription Database $\cdot$ Population-based registries $\cdot$ Prescription database $\cdot$ Type 1 diabetes

\section{Abbreviations \\ NCDR Norwegian Childhood Diabetes Registry \\ NorPD Norwegian Prescription Database}

\section{Introduction}

The incidence of type 1 diabetes diagnosed before 15 years of age has increased in most studied populations over the past 
two to three decades, with an average increase per year of approximately $2.5-3.0 \%$ during the 1990 s and 2000s [1-3]. The incidence has tended to rise more steeply, in relative terms, in some of the low prevalence countries, but there are wide variations in the rates of change between countries and between periods [3-6]. The most recent trends from Sweden and Finland, the countries with the highest incidence, have indicated that the incidence has ceased to increase in the past few years $[7,8]$.

After Finland and Sweden, Norway is among the countries with the highest incidence of childhood-onset type 1 diabetes in the world [2,4]. Data published previously showed a stepwise but overall increasing trend during the period 1973-2003, increasing from 19.1 per 100,000 person-years in 1973 to 28.9 per 100,000 person-years in 2001-2003 [2,9]. Regional variation within Norway has been reported $[9,10]$.

The aim of this study was to describe the incidence rates of type 1 diabetes with onset before 15 years of age in Norway in the period 1989-2012 and to assess the regional variation within the country for the period 2004-2012. Furthermore, we took advantage of the nationwide Norwegian Prescription Database (NorPD), established in 2004, as a secondary source of cases, allowing estimation of the completeness of ascertainment.

\section{Methods}

The Norwegian Childhood Diabetes Registry In the Norwegian healthcare system all children aged 0-14.9 years with suspected diabetes are referred to a paediatric department. The Norwegian Childhood Diabetes Registry (NCDR) includes all new cases of childhood-onset diabetes, reported from all the paediatric departments in Norway, based on informed consent from the child and/or the child's parents. Cases are included as type 1 diabetes in the NCDR based on a clinical diagnosis of type 1 diabetes, using the first insulin injection as the date of diagnosis, and residence in Norway at the time of diagnosis, in accordance with the EURODIAB criteria.

NorPD The NorPD is a national population-based prescription drug registry established at the Norwegian Institute of Public Health in 2004. It captures all prescriptions dispensed at pharmacies to individual patients in open care, and all pharmacies in Norway are obliged by law to forward prescription data to the NorPD [11]. The first dispensation of insulin (insulins or insulin analogues, ATC-code A10A) from a pharmacy was assumed to be near the time of diagnosis of type 1 diabetes for the purpose of estimating completeness of ascertainment during the period 2005-2008 (excluding prevalent users in 2004 to ensure that we only included incident users of insulin from 2005 to 2008).
Statistical analysis The size of the population in each calendar year, for each sex and 1 year age group, was obtained from Statistics Norway (www.ssb.no) and used to estimate the number of person-years in each subgroup.

The two registers were linked via the 11 digit personal identification code given to each Norwegian citizen; the number of children recorded only in the NCDR, only in the NorPD, or in both, was counted for each calendar year from 2005 to 2008. Completeness of registration in the NCDR was assessed by the capture-recapture method, which requires that the two sources are independent; none of the sources, however, have to be complete [12]. Formulae for ascertainment and $95 \%$ CIs are provided in the footnote of Table 1. For the calculation of incidence rates, only cases recorded by the primary register (NCDR) were included.

The effects of age, sex and calendar periods were modelled using Poisson regression with Stata software, version 12 (StataCorp LP, College Station, TX, USA). Various models were fitted, including sex, age group, calendar period and county of residence at diagnosis. Age was modelled as a categorical variable grouped in 5-year intervals for most analyses. We also assessed the influence of modelling age in 15 age groups spanning 1 year each. The calendar period was modelled with linear splines to allow estimation of slopes (change per year) and changes in slopes between time segments. Visual inspection of plots of yearly rates clearly suggested three time segments. This was confirmed by plotting expected rates from models with restricted cubic splines using five knots and Harrell's rule for placement of knots (default option in Stata's mkspline procedure for restricted cubic splines) (electronic supplementary material [ESM] Fig. 1). The latter model is more flexible. We also explored two-way interactions among the four study variables (using 5-year categories for age). Likelihood ratio tests were used to test the influence of region, sex and age.

The study was approved by the Regional Ethics Committee and the National Data Inspectorate.

\section{Results}

Time trend in incidence, 1989-2012 Figure 1 shows the observed incidence rates for each of the years between 1989 and 2012, indicating three distinct segments with different slopes. From 1989 to 1996, the average incidence rate was 22.6 per 100,000 person-years $(95 \%$ CI $21.4,23.7)$, and the estimated change per year was $1.8 \%(95 \%$ CI $-0.07,3.6$; $p=0.059$ ). From 1996 to 2004, the average incidence rate was 28.4 per 100,000 person-years $(95 \%$ CI $27.3,29.6)$, with an estimated change per year of $3.4 \%(95 \%$ CI $2.2,4.7$; $p<0.0001$ ). From 2004 to 2012, the average incidence rate was 32.7 per 100,000 person-years $(95 \%$ CI $31.5,34.0)$, with an estimated change per year of $0.3 \%(95 \%$ CI $-0.9,1.6$; 
Table 1 Number of newly diagnosed cases of type 1 diabetes in children aged 0-14.9 years, registered in the NCDR and NorPD

\begin{tabular}{|c|c|c|c|c|c|c|c|}
\hline \multirow[t]{2}{*}{ Year } & \multicolumn{3}{|c|}{ Registered new cases } & \multirow{2}{*}{$\begin{array}{l}\text { Only registered } \\
\text { in } \mathrm{NCDR}^{\mathrm{a}}\end{array}$} & \multirow{2}{*}{$\begin{array}{l}\text { Only registered } \\
\text { in NorPD }\end{array}$} & \multirow{2}{*}{$\begin{array}{l}\text { Completeness } \\
\text { of } \mathrm{NCDR}^{\mathrm{b}}, \%\end{array}$} & \multirow[t]{2}{*}{$95 \% \mathrm{CI}$} \\
\hline & NCDR, $M$ & NorPD, $n$ & $\begin{array}{l}\text { In both NCDR } \\
\text { and NorPD, } m\end{array}$ & & & & \\
\hline 2005 & 288 & 336 & 285 & 3 & 51 & 84.8 & $84.4,85.2$ \\
\hline 2006 & 288 & 306 & 287 & 1 & 19 & 93.8 & $93.6,93.9$ \\
\hline 2007 & 294 & 305 & 289 & 5 & 16 & 94.8 & $94.4,95.1$ \\
\hline 2008 & 291 & 309 & 280 & 11 & 29 & 90.6 & $90.0,91.3$ \\
\hline Total & 1,161 & 1,256 & 1,141 & 20 & 115 & 90.8 & $90.6,91.1$ \\
\hline
\end{tabular}

${ }^{\text {a }}$ Some of these cases might have been diagnosed late in the year before and might not have been registered in the NorPD in the same calendar year; two have emigrated; three have an incorrect 11 digit patient identification number

${ }^{\mathrm{b}}$ The total number of cases (including unobserved cases), $N$, was estimated as: $N=[(M+1)(n+1) /(m+1)]-1$; completeness of ascertainment for NCDR was then estimated as $M / N$, and the corresponding $95 \% \mathrm{CI}$ was calculated using the following approximate formula for the variance of $N: \operatorname{Var}(N)=\left[(M+1)(n+1)(M-m)(n-m) /(m+1)^{2}(m+2)\right]$, where $M$ is the observed number in the NCDR, $n$ is the observed number in the NorPD, and $m$ is the number in both the NCDR and the NorPD

$p=0.64)$. Finally, we found that the difference in slope between the first two time segments was not significant ( $p=0.24$ ), while the change per year during 2004-2012 was significantly different from the change per year during 1996-2004 $(p=0.006)$.

There was an unexpected single peak in incidence in 2009 (Fig. 1). We explored whether this was consistent over age groups (ESM Fig. 2a), sex (ESM Fig. 2b) and county of residence (not shown) but found no consistent pattern. Slight differences in observed trends among sex, age group and county (none of which were statistically significant) resulted in the observed pattern in Fig. 1. Furthermore, formal modelling of the yearly incidence in the period 2004-2012 (eight degrees of freedom test) was not significant $(p=0.74)$. When considering 2008, 2009 and 2010 in isolation, 2009 was not significantly different from either of the two

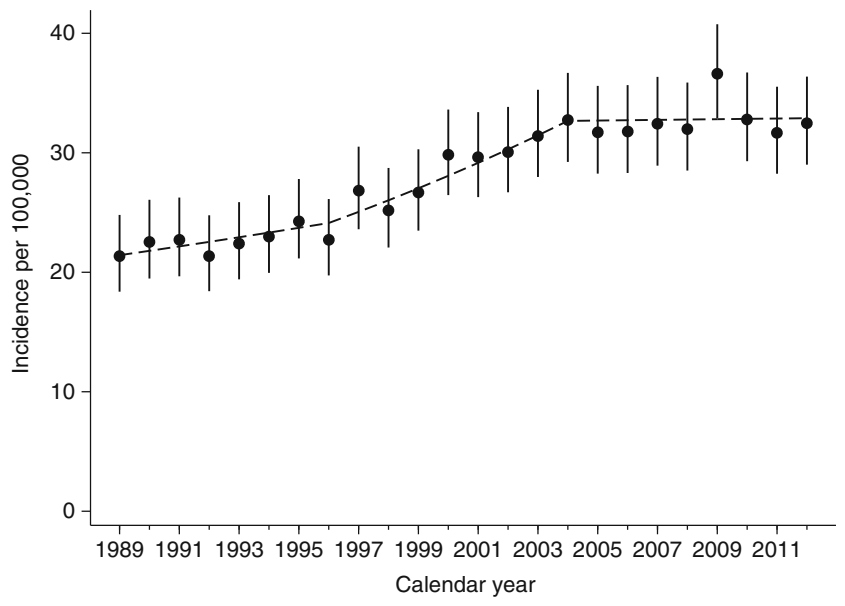

Fig. 1 Yearly observed type 1 diabetes incidence rates with $95 \%$ CIs for children in Norway during 1989-2012. The broken line represents the expected rates from Poisson regression models with linear splines and knots at 1996 and 2004 neighbouring years $(p=0.09, p=0.19$, respectively). Collectively, these results support the notion that the observed 2009 peak might have been a chance finding.

Variation by age, sex and region, 2004-2012 Because the incidence by age, sex and county for periods up to 2003 has been published previously [2], the remainder of the results are presented for the period 2004-2012 (data in Table 2 and ESM Table 1). The incidence was slightly higher in boys (33.9 per 100,000 person-years; $95 \%$ CI 32.2, 35.7) than in girls (31.4 per 100,000 person-years; 95\% CI 29.7, 33.2) (Table 2). After adjustment for age and period, the boys had an estimated $8 \%$ higher incidence compared with girls $(95 \%$ CI $0.1,16$; $p=0.047)$. In both sexes, the highest incidence was at age 10-14 years (ESM Table 1). The age-specific incidence rates during 2004-2012 were 19.2, 35.2 and 43.1 per 100,000

Table 2 Age- and sex-specific incidence rates of type 1 diabetes in children aged 0-14.9 years in the NCDR, 2004-2012

\begin{tabular}{llll} 
Age group & \multicolumn{2}{l}{$\begin{array}{l}\text { Incidence rate of type } 1 \text { diabetes in Norway per 100,000 } \\
\text { person-years }(95 \% \text { CI) }\end{array}$} \\
\cline { 2 - 4 } & Boys & Girls & Total \\
\hline 2004 & $32.1(27.4,37.7)$ & $33.4(28.4,39.2)$ & $32.7(29.2,36.7)$ \\
2005 & $33.7(28.8,39.4)$ & $29.6(24.9,35.1)$ & $31.7(28.2,35.5)$ \\
2006 & $34.0(29.1,39.7)$ & $29.4(24.8,34.9)$ & $31.8(28.3,35.6)$ \\
2007 & $33.0(28.1,38.6)$ & $31.9(27.1,37.6)$ & $32.5(28.9,36.4)$ \\
2008 & $32.9(28.1,38.6)$ & $31.2(26.4,36.8)$ & $32.1(28.6,36.0)$ \\
2009 & $38.7(33.5,44.8)$ & $34.4(29.3,40.3)$ & $36.6(32.9,40.8)$ \\
2010 & $35.9(30.9,41.8)$ & $29.5(24.9,35.0)$ & $32.8(29.3,36.7)$ \\
2011 & $33.5(28.6,39.1)$ & $29.8(25.2,35.3)$ & $31.7(28.2,35.5)$ \\
2012 & $31.5(26.8,37.0)$ & $33.5(28.6,39.3)$ & $32.5(29.0,36.4)$ \\
$2004-2012$ & $33.9(32.2,35.7)$ & $31.4(29.7,33.2)$ & $32.7(31.5,34.0)$
\end{tabular}


person-years, for the $0-4,5-9$ and 10-14 year olds, respectively (ESM Table 1). The incidence started out very low for those below 1 year of age and increased rapidly to peak at around 10-11 years of age. There was an apparent drop after 11 years of age in girls but not in boys (ESM Fig. 3). No significant two-way interactions among sex, age and period were found in Poisson regression modelling, suggesting that the above-mentioned results for period, sex and age were consistent in subgroups. Also, goodness-of-fit tests (deviance and Pearson) suggested adequate fit of models without interactions.

We observed a significant variation among the 19 counties in Norway (likelihood ratio test with 18 degrees of freedom, after adjustment for age and sex; $p<0.001$ ). The county-wise incidence rates with $95 \%$ CIs and change per calendar year are shown in Table 3, and rates are shown in a colour-coded map in ESM Fig. 4. Aust-Agder, in the southern part of Norway, had the highest incidence at 45.7 per 100,000 person-years. Oslo had the lowest incidence at 22.3 per 100,000 person-years. Poisson regression modelling suggested no significant county by calendar period interactions, suggesting that the time trends were relatively homogeneous among counties. When analysing percentage change per year the largest observed increase was in Finnmark $(8.1 \% ; p=0.194)$, and the largest decrease was observed in Østfold $(-6.1 \% ; p<0.053)$; neither were significant.

Ascertainment, 2005-2008 During 2005-2008 the NorPD contained data on first-time insulin dispensed for 115 subjects not reported to the NCDR. The completeness of ascertainment in the NCDR was calculated to be $91 \%$ for this study period (Table 1). The completeness of ascertainment in the NorPD was calculated to be $98.4 \%$, and the total ascertainment from both sources in the period 2005-2008 was $99.8 \%$.

Regarding the 51 cases identified exclusively from the NorPD, 25 (49\%) of the cases were clustered at the beginning of 2005. This might reflect that these patients had their clinical diagnosis in 2004. Regarding the 29 cases exclusively identified from the NorPD in 2008, $16(55 \%)$ were clustered at the end of 2008. The cases exclusively found in the NorPD $(n=115)$ had a mean age of 10.7 years (SD 3.6) and 52\% were boys. They were spread among 17 of 19 counties, but $63 \%$ $(n=72)$ were clustered in five of 19 counties: Hordaland, Rogaland, Akershus, Vest-Agder and Sør-Trøndelag. This might reflect local difficulties as a delay in registration of new cases of type 1 diabetes in the NCDR.

The cases exclusively registered in the NCDR $(n=20)$ had a mean age of 9.6 years (SD 4.3) and 30\% were boys. They came from eight out of 19 counties, and $40 \%(n=8)$ were clustered in one county (Telemark).

\section{Discussion}

Our results show that the incidence rate among Norwegian children was stable at about 33 per 100,000 person-years during 2004-2012, and that the time trend in this period was
Table 3 Age- and sexstandardised incidence rate of childhood-onset type 1 diabetes in the 19 counties of Norway, 2004-2012

${ }^{\text {a }}$ Sum of the mean population size in each single year during 2004-2012

b $95 \%$ CI calculated using the formula $\mathrm{SE}\left(\log _{e} \mathrm{IR}\right)=1 / \sqrt{\mathrm{D}}$, in which $\mathrm{D}$ is the number of cases and IR is the incidence rate

${ }^{\mathrm{c}}$ Adjusted for sex and age (5-year groups)

\begin{tabular}{lcclc}
\hline County & Cases, $n$ & Person-years ${ }^{\mathrm{a}}$ & $\begin{array}{l}\text { Incidence rate per 100,000 } \\
\text { person-years }(95 \% \mathrm{CI})^{\mathrm{b}}\end{array}$ & $\begin{array}{l}\text { Percentage } \\
\text { change per year }\end{array}$ \\
\hline Østfold & 145 & 444,461 & $32.6(27.7,38.4)$ & $-6.1(-11.9,0.1)$ \\
Akershus & 285 & 976,227 & $29.2(26.0,32.8)$ & $4.7(0.1,9.5)$ \\
Oslo & 194 & 869,882 & $22.3(19.4,25.7)$ & $-1.4(-6.7,4.1)$ \\
Hedemark & 90 & 296,330 & $30.4(24.7,37.3)$ & $0.1(-6.8,9.4)$ \\
Oppland & 113 & 292,716 & $38.6(32.1,46.4)$ & $0.9(-6.1,8.4)$ \\
Buskerud & 140 & 423,506 & $33.1(28.0,39.0)$ & $-5.8(-11.7,0.4)$ \\
Vestfold & 136 & 380,839 & $35.7(30.2,42.2)$ & $0.8(-5.6,7.6)$ \\
Telemark & 113 & 269,258 & $42.0(34.9,50.5)$ & $-1.8(-8.5,5.5)$ \\
Aust-Agder & 85 & 186,067 & $45.7(36.9,56.5)$ & $4.6(-3.7,13.6)$ \\
Vest-Agder & 101 & 305,060 & $33.1(27.2,40.2)$ & $1.5(-5.9,9.5)$ \\
Rogaland & 258 & 796,851 & $32.4(28.7,36.6)$ & $-1.2(-5.8,3.5)$ \\
Hordaland & 265 & 834,772 & $31.7(28.1,35.8)$ & $-1.1(-5.6,3.6)$ \\
Sogn og Fjordane & 80 & 192,259 & $41.6(33.4,51.8)$ & $7.9(-1.0,17.5)$ \\
Møre og Romsdal & 159 & 432,715 & $36.7(31.5,42.9)$ & $2.9(-3.1,9.3)$ \\
Sør-Trøndelag & 148 & 486,429 & $30.4(25.9,35.7)$ & $7.4(0.9,14.4)$ \\
Nord-Trøndelag & 73 & 230,987 & $31.6(25.1,39.8)$ & $-2.4(-10.7,6.7)$ \\
Nordland & 154 & 399,105 & $38.6(32.9,45.2)$ & $-1.8(-7.6,4.4)$ \\
Troms & 105 & 267,989 & $39.2(32.4,47.4)$ & $1.2(-6.0,9.0)$ \\
Finnmark & 42 & 129,745 & $32.4(23.9,43.8)$ & $0.4(-1.0,1.9)$ \\
Total & 2,686 & $8,215,198$ & $32.7(31.5,34.0)$ &
\end{tabular}


significantly different from that during 1996-2004. Our nationwide registry has registered incident cases prospectively since 1989 using standard criteria and methods. Other notable results include significant regional variation, discussed in more detail below. We have also estimated ascertainment in the NCDR using the nationwide NorPD as an independent source for the period 2005-2008.

Regional variation has previously been described in Norway $[9,10]$. The current data show a slightly different pattern than in previous years. While the southernmost county in Norway, Vest-Agder, previously had the highest incidence, and the neighbouring Aust-Agder county had an incidence near the country average [10], the current pattern is reversed. Oslo had the lowest incidence; in the time period 1989-1998, however, Oslo had a low, but not the lowest, incidence [10]. The relatively small population sizes make it difficult to study potential causes in any county. The reason for the low incidence in Oslo is also unknown. Compared with other counties, however, Oslo has a relatively high proportion of ethnic groups known from other studies to have a lower incidence of type 1 diabetes. Finnmark, the northernmost county that had the lowest incidence in 1989-1998, is still among the counties with the lowest incidence. Our present data are based on county of residence at the time of diagnosis. We were not able to take into account whether or when some individuals might have changed county of residence before diagnosis; however, most people in Norway tend to move within counties when they move house. Future analyses should investigate small area variations and the potential roles of factors such as population density, urban/rural setting, latitude and climate.

The strength of this study is the nationwide, populationbased design. The linking of two independent populationbased registries ensured the capture of cases with new-onset type 1 diabetes.

The study disclosed that some of the cases in the NCDR were registered with an incorrect personal identification number, and clerical errors may lie behind the less than $100 \%$ estimated completeness of ascertainment. This provides an important impetus for us to continue to work with quality assurance at all levels of our registry. It is also possible that a small number of children with prevalent type 1 diabetes might have emigrated from another country to Norway and incorrectly been counted as incident type 1 diabetes in the NorPD. The latter would thus have biased the estimated completeness of the NCDR downwards. In future studies, we hope to be able to correct any such bias.

In this study we did not include children with type 2 or other forms of diabetes in the NCDR, although a few cases in the NorPD might have been included. This limitation of not removing the small number of cases in the NorPD where insulin was being given for conditions other than type 1 diabetes (e.g. type 2 diabetes, cystic fibrosis or steroid-induced diabetes) might have led to an underestimation of the completeness of the NCDR.

There are clear indications of geographic differences in the trends in incidence of childhood-onset type 1 diabetes, but the overall annual increase is estimated to be around $2.5-3 \%$ $[3,13,14]$. Several European studies have suggested, in relative terms, that increases are greatest among children aged $0-4$ years $[5,15-17]$. This has never been the case in Norway, where the highest increase has always been in the age group $10-14$ years.

Our result is in accordance with the most recent observations from Sweden [7] and Finland [8], as well as from some lower incidence countries such as the Czech Republic [18].

This 9-year period of no apparent increase in incidence suggests that time trends in exposure to unknown factors conferring an increased risk of type 1 diabetes have levelled off, or that factors conferring protection have ceased decreasing in Norway. As non-genetic factors able to explain changing trends in the epidemiology of type 1 diabetes have not been established, we find it difficult to speculate about the explanations, but we hope that these observations can stimulate generation of new hypotheses to be tested in future aetiological studies.

Funding The NCDR is financed by the South-Eastern Norway Regional Health Authority. The funding source has no role in data collection or analysis, or in any other aspects of the study. The NorPD was funded by the National Institute of Public Health.

Duality of interest The authors declare that there is no duality of interest associated with this manuscript.

Contribution statement TS, GJ and LCS initiated and designed this study. TS collected the data, contributed to the data analysis and interpretation of the results, and wrote the manuscript. LCS analysed the data, contributed to the interpretation of the results and revision of the manuscript. AKD contributed to the data analysis, interpretation of the results and revision of the manuscript. GJ contributed to the interpretation of the results and revision of the manuscript. HS contributed to the interpretation of the results and revision of the manuscript. All authors critically revised the manuscript and approved the final version of the manuscript for submission.

\section{References}

1. The DIAMOND Project Group (2006) Incidence and trends of childhood type 1 diabetes worldwide 1990-1999. Diabet Med 23: $857-866$

2. Aamodt G, Stene LC, Njolstad PR, Sovik O, Joner G (2007) Spatiotemporal trends and age-period-cohort modeling of the incidence of type 1 diabetes among children aged $<15$ years in Norway 1973-1982 and 1989-2003. Diabetes Care 30:884-889

3. Patterson CC, Dahlquist GG, Gyurus E, Green A, Soltèsz G (2009) Incidence trends for childhood type 1 diabetes in Europe during 
1989-2003 and predicted new cases 2005-20: a multicentre prospective registration study. Lancet 373:2027-2033

4. Soltèsz G, Dahlquist GG (2006) Global trends in childhood type 1 diabetes. In: Gan D (ed) Diabetes atlas, 3rd edn. International Diabetes Federation, Brussels, pp 154-158

5. Harjutsalo V, Sjoberg L, Tuomilehto J (2008) Time trends in the incidence of type 1 diabetes in Finnish children: a cohort study. Lancet 371:1777-1782

6. Patterson CC, Gyurus E, Rosenbauer J et al (2012) Trends in childhood type 1 diabetes incidence in Europe during 1989-2008: evidence of non-uniformity over time in rates of increase. Diabetologia 55:2142-2147

7. Berhan Y, Waernbaum I, Lind T, Mollsten A, Dahlquist G (2011) Thirty years of prospective nationwide incidence of childhood type 1 diabetes: the accelerating increase by time tends to level off in Sweden. Diabetes 60:577-581

8. Harjutsalo V, Sund R, Knip M, Groop PH (2013) Incidence of type 1 diabetes in Finland. JAMA 310:427-428

9. Joner G, Sovik O (1989) Increasing incidence of diabetes mellitus in Norwegian children 0-14 years of age 1973-1982. Diabetologia 32: $79-83$

10. Joner G, Stene LC, Sovik O (2004) Nationwide, prospective registration of type 1 diabetes in children aged $<15$ years in Norway 1989-1998: no increase but significant regional variation in incidence. Diabetes Care 27:1618-1622
11. Furu K (2008) Establishment of the nationwide Norwegian Prescription Database (NorPD) - new opportunities for research in pharmacoepidemiology in Norway. Nor J Epidemiol 18:129-136

12. McCarty DJ, Tull ES, Moy CS, Kwoh CK, Laporte RE (1993) Ascertainment corrected rates: applications of capture-recapture methods. Int J Epidemiol 22:559-565

13. Onkamo P, Vaananen S, Karvonen M, Tuomilehto J (1999) Worldwide increase in incidence of type I diabetes - the analysis of the data on published incidence trends. Diabetologia 42:1395-1403

14. Eurodiab, ACE Study Group (2000) Variation and trends in incidence of childhood diabetes in Europe. Lancet 355:873-876

15. Tuomilehto J, Virtala E, Karvonen M et al (1995) Increase in incidence of insulin-dependent diabetes mellitus among children in Finland. Int J Epidemiol 24:984-992

16. Gardner SG, Bingley PJ, Sawtell PA, Weeks S, Gale EA (1997) Rising incidence of insulin dependent diabetes in children aged under 5 years in the Oxford region: time trend analysis. The Bart's-Oxford Study Group. BMJ 315:713-717

17. Dahlquist G, Mustonen L (2000) Analysis of 20 years of prospective registration of childhood onset diabetes time trends and birth cohort effects. Swedish Childhood Diabetes Study Group. Acta Paediatr 89: $1231-1237$

18. Cinek O, Kulich M, Sumnik Z (2012) The incidence of type 1 diabetes in young Czech children stopped rising. Pediatr Diabetes 13:559-563 